\title{
Coming Out Mechanism of Steel Shaft from Ceramic Sleeve
}

\author{
Nao-Aki NODA, ${ }^{*}$ Yuanming XU, Dedi SURYADI, Yoshikazu SANO and Yasushi TAKASE \\ Dept. of Mechanical and Control Engineering, Kyushu Institute of Technology, 1-1 Sensui-cho, Tobata-ku, Kitakyushu-shi, 804- \\ 8550 Japan.
}

(Received on September 27, 2015; accepted on November 12, 2015)

\begin{abstract}
Ceramic rollers can be used in the heating furnace conveniently because of its high temperature resistance. The new roller consists of ceramic sleeve and steel shaft connected only under a small shrink fitting ratio because of the brittleness. In the previous study, simulation of coming out of the shaft from the sleeve was performed, but only small number of loading cycle can be considered because of large computational time. To analyze the coming out problem more efficiently, in this paper, the two-dimensional shrink fitted structures are considered. Then, the effects of the magnitude of load and shrink fitting ratio are investigated under large number of loading cycle. Finally, the coming out mechanism is discussed for larger number of cycles by focusing on the shear stress and displacement at the joint end. The coming out occurs when the negative shear stress is unstable. On the other hand, the coming out does not occur when the positive shear stress is stable with little fluctuation.
\end{abstract}

KEY WORDS: ceramic roller; coming out mechanism; shrink fitting; finite element method.

\section{Introduction}

Steel conveying rollers are used in the heating furnace for producing high-quality steel plates for automobiles. The conventional roller material is steel with ceramic spray coating on the outside of sleeve. To reduce the temperature, inside of the roller is cooled by water. However the thermal expansion mismatch may exceed the adhesion strength of the ceramic layer and causes failure on the roller surface such as crack, peeling, and wearing. ${ }^{1)}$ Therefore, the life of the roller becomes short. A new ceramic roller consists of steel shaft at both ends and ceramic sleeve having high heat resistance, high corrosion resistance and high wear resistance. Air circulation is applied on the inside roller. The ceramic sleeve may prevent defects caused by coating, ${ }^{2,3)}$ and therefore, the roller life can be extended significantly. Since both adhesive bonding and metal bonding have very low strength under high temperature, only shrink fitting can be applied for the ceramic sleeve and steel shaft connection. Several previous studies suggested that the shrink fitting may be the most suitable joining method for cylindrical ceramic and the maintenance cost and replacement time of the shaft can be reduced. ${ }^{4-6)}$ However, since the thermal expansion coefficient of steel is about four times larger than the one of ceramic, only a small shrink fitting ratio can be used to prevent fractures due to the shaft expansion. ${ }^{7-14)}$

Several studies are available for contact failure regarding the shrink fitting assembly for a gear hub and shaft, ${ }^{15)}$ for rotating thermos elastoplastic. ${ }^{16)}$ Previously, authors have discussed the effects of the shrink fitting ratio and the friction coefficient upon the coming out behavior of the

\footnotetext{
* Corresponding author: E-mail: noda@mech.kyutech.ac.jp DOI: http://dx.doi.org/10.2355/isijinternational.ISIJINT-2015-558
}

shaft. ${ }^{17,18)}$ In this study, the roller rotation is replaced by shifting load in the circumferential direction on the fixed roll. However, since the $3 \mathrm{D}$ simulation needs very large computational time, it is actually impossible to calculate the results when number of cycle $\mathrm{N}$ is larger than 10 . Therefore, to predict the coming out behavior is still being problematic.

In this paper, the two dimensional model subjected to alternate loading will be considered instead of the three dimensional model subjected to rotary bending so that the computational time can be greatly reduced. If the coming out behavior of the shaft can be simulated numerically by using this efficient modelling, the coming out may be predicted from stable simulation results under large number of loading cycle. In addition, the coming out mechanism will be discussed focusing on contact shear stress and displacement at the joint end.

\section{Analysis Condition}

\subsection{Analysis Model}

Figure 1 shows the dimensions of the roller. In this study, a simplified model will be considered to reduce computational time so that the results can be obtained until the large number of loading cycle N. Figure 2 shows 3D model previously used where the load is shifting in the circumferential direction. ${ }^{17,18)}$ Figure 3 shows 3D model subjected to alternate load, which is named 3D alternate model where the sleeve is replaced by the rigid body and alternate load is applied at the shaft end. Figure 4 shows 2D model subjected to alternate load, which is named 2D alternate model. Figure 5 illustrates how to simplify the 3D model to the 2D model. Here, the hollow shaft shrink-fitted to sleeve is replaced by the solid $2 \mathrm{D}$ shaft sandwiched by the outer rigid bodies. In the $2 \mathrm{D}$ model, hollow structures as shown in Figs. 2 and 3 are not possible because they 
cannot sustain the compressive load due to shrink fitting. Therefore, we consider 2D shaft as shown in Fig. 4 which consists of bimaterial $E_{s h}^{1}$ and $E_{s h}^{2}$. Here, $E_{s h}^{1}=210 \mathrm{GPa}$ is Young's modulus of steel, and $E_{s h}^{2}$ is Young's modulus of a composite, which is determined in the following equation based on the rules of mixture.

$$
\begin{aligned}
E_{s h}^{2} & =E_{s h}^{1} \frac{A_{1}}{A_{1}+A_{2}}+E_{2} \frac{A_{2}}{A_{1}+A_{2}} \\
& =E_{s h}^{1} \frac{A_{1}}{A_{1}+A_{2}}=51.55 \mathrm{MPa}
\end{aligned}
$$

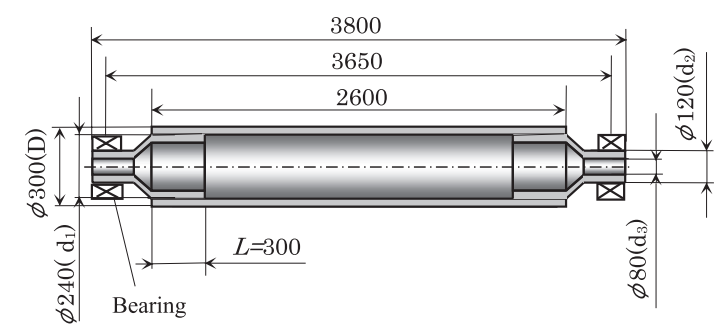

Fig. 1. Structure and dimensions of a real ceramic roller ( $\mathrm{mm})$.
Here, $E_{2}=0$ is Young's modulus of the hollow part. Area $A_{1}$ is the cross-sectional area of the shaft, while area $A_{2}$ is the cross-section of the hollow part.

Table 1 shows the material properties of the models. For $3 \mathrm{D}$ model, the shaft material is steel. For 2D model, the material of $2 \mathrm{D}$ shaft is the composite as described above, and the outer plate is rigid.

\subsection{Boundary Conditions and Analysis Method}

In $3 \mathrm{D}$ model, the roller is subjected to distributed load $\mathrm{w}=30 \mathrm{~N} / \mathrm{mm}$ on the sleeve part due to the weight of the conveying steel plate. The distributed load is replaced by a supporting reaction force $P=18 \mathrm{kN}$ at the end of shaft portion. For 2D model, the point load in three-dimension model is replaced by the distributed load as shown in Fig. 4. Here, 2D model has a unit thickness which corresponds to 120 $\mathrm{mm}$ width and the standard load $18 \mathrm{kN}$ is represented by $150 \mathrm{~N} / \mathrm{mm}$ considering the diameter of the shaft. In previous 3D modelling, the roller rotation was simulated by the load shitting in the circumferential direction on the fixed roller at certain time interval of the rotational angle $\theta$.

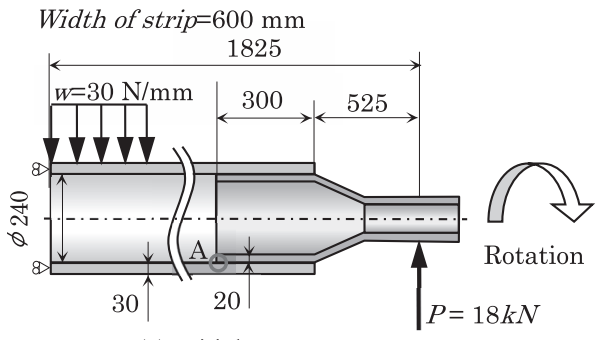

(a) Initial state



(b) $180^{\circ}$ rotation

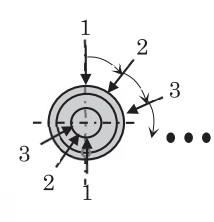

(c) Right view

Fig. 2. Three-dimensional rotating loading model (Model 3D-rot.).

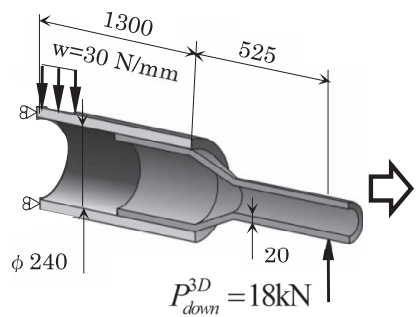

(a) Initial state

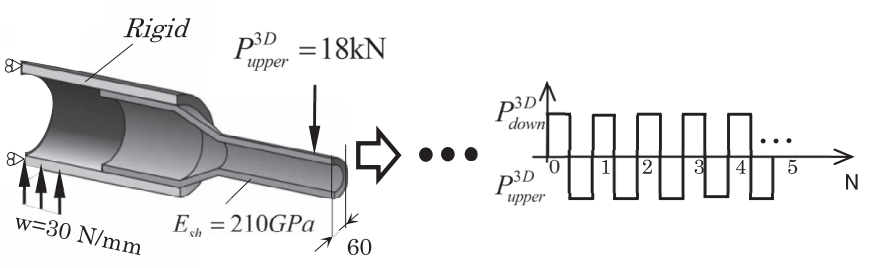

(b) Alternate loading (c) Loading cycle

Fig. 3. Three-dimensional alternate loading model (Model 3D-alt.).

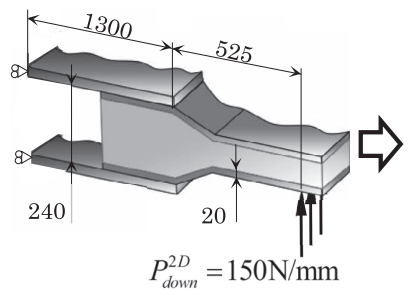

(a) Initial state

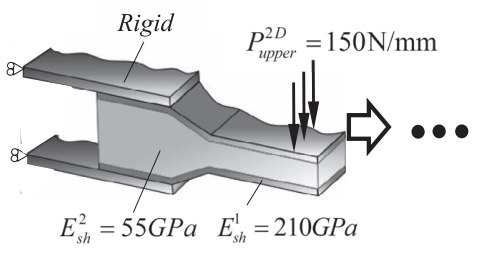

(b) Alternate loading

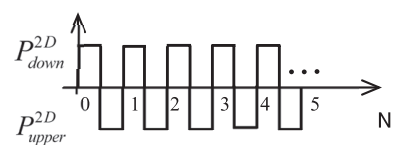

(c) Loading cycle

Fig. 4. Two-dimensional alternate loading model (Model 2D-alt.).

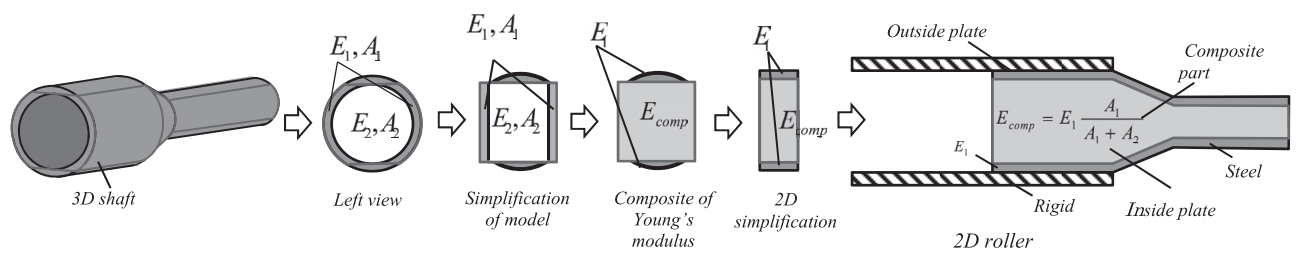

Fig. 5. Simplified two-dimensional model of the roller. 
The purpose of this study is to realize the coming out for large number of cycle by the numerical simulation. In this study, the coming out is considered under room temperature because the coming out occurs more easily. If we want to consider the roller in the heating furnace, equivalent shrink fitting ratios may be applied by considering the shaft expansion. The shrink fitting ratio of the $2 \mathrm{D}$ model is equivalent to the one of the $3 \mathrm{D}$ model. The shrink fitting ratio $\delta / \mathrm{d}$ is defined as height difference $\delta$ divided by height $\mathrm{d}=240 \mathrm{~mm}$. The shrink fitting is considered in the range $\delta / \mathrm{d}=0.01 \times 10^{-3}-1.0 \times 10^{-3}$. The ratio $0.2 \times 10^{-3}$ is used as a reference value.

Since the load condition does not reach the plastic region of the steel shaft in 3D model, elastic analysis will be applied to the simplified 2D model. Here, static structural analysis is performed to the models by using MSC. Marc/ Mentat 2011 with full Newton-Raphson iterative spare solver of multifrontal method. The total number of elements is 15580 . A half model is considered due to the symmetry.

Table 1. Material properties.

\begin{tabular}{cccccc}
\hline Model & \multicolumn{3}{c}{ 3D-alt., 2D-alt. } & \multicolumn{2}{c}{ 3D-rot. } \\
\hline & Sleeve & & Shaft & Sleeve & Shaft \\
\hline & Rigid & Steel & $\begin{array}{c}\text { Composite } \\
\text { part }\end{array}$ & Ceramics & Steel \\
\hline $\begin{array}{c}\text { Young's modulus } \\
{[\mathrm{GPa}]}\end{array}$ & $\infty$ & 210 & 55 & 300 & 210 \\
$\begin{array}{c}\text { Poisson's ratio } \\
\text { Tensile strength } \\
{[\mathrm{MPa}]}\end{array}$ & 1 & 0.3 & 0.3 & 0.28 & 0.3 \\
$\begin{array}{c}\text { Mass density } \\
{\left[\mathrm{kg} / \mathrm{m}^{3}\right]}\end{array}$ & 0 & 600 & - & 500 & 600 \\
\hline
\end{tabular}

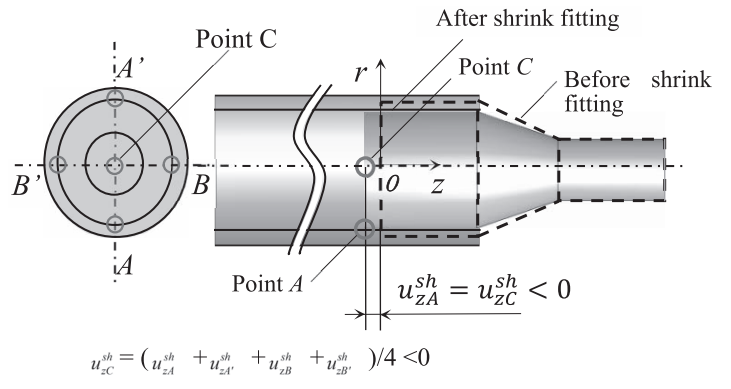

(a) Displacement (Model 3D-rot.)

\section{Deformation and Displacement of the Shaft under Different Shrink Fitting Ratios and Bending Loads}

\subsection{Deformation and Stress of the Shaft Due to Shrink Fitting}

Figure 6 shows deformation of the shaft due to shrink fitting. In this analysis, the coming out will be discussed by using the $\mathrm{z}$-displacement at point $\mathrm{C}$ as shown in Fig. 6(a). Here, z-displacement $u_{\mathrm{zC}}$ for 3-D model is defined by $u_{z C}^{s h}=\left(u_{z A}^{s h}+u_{z A}^{s h}+u_{z B}^{s h}+u_{z B}^{s h},\right) / 4=u_{z A}^{s h}<0$ as shown in Fig. 6(a). For 2D model, the z-displacement is defined at the center of inner plate at point $\mathrm{C}$. This point $\mathrm{C}$ is used as a reference point of the displacement.

Figures 6(a), 6(b) shows the displacement of the shaft due to shrink fitting. Since the shaft is compressed in the r-direction, point A of the shaft enters into the sleeve. For $3 \mathrm{D}$ model, the negative displacement occurs as $u_{z A}^{s h}=u_{z C}^{s h}<0$, and for 2D model, the negative displacement occurs as $u_{z C}^{s h}<$ $u_{z A}^{s h}<0$. Figure 7 shows stress $\sigma_{\mathrm{r}}$ along the contact surface due to shrink fitting. Maximum stress $\sigma_{\mathrm{r}}=105 \mathrm{MPa}$ appears at the shaft end of 3D model. The maximum stress $\sigma_{\mathrm{r}}=175$ $\mathrm{MPa}$ appears at the outer plate end of 2D model. It is seen that stress concentration is quite large for 2D model.

Shear stress $\tau_{\mathrm{rz}}$ is also shown in Figs. 7(a), and 7(b). Although the shaft is extended in the axial direction by the compressive stress $\sigma_{\mathrm{r}}$ due to shrink fitting, shear stress $\tau_{\mathrm{rz}}$ is working to prevent the elongation as shown in Figs. 7(a), 7(b). Maximum shear stress $\tau_{\mathrm{rz}}= \pm 16 \mathrm{MPa}$ appears at the shaft end surface and $\tau_{\mathrm{rz}}= \pm 17 \mathrm{MPa}$ appears at the plate end surface.

\subsection{Deformation and Displacement of the Shaft Due to Alternate Loading}

In this chapter we consider two points $\mathrm{A}$ and $\mathrm{C}$ as shown

Fig. 6. Shermatic view of displacement of the shaft and the inside plate due to shrink fitting.

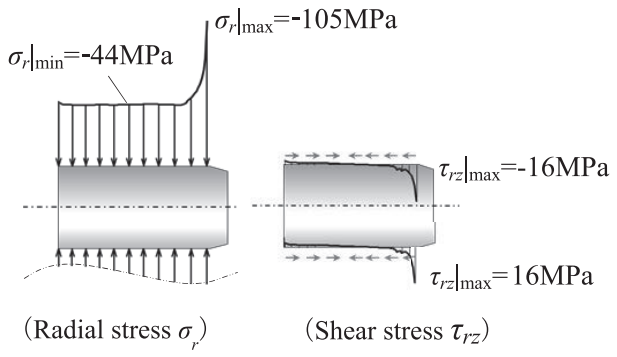

(a) Stress on the shaft (Model 3D-rot.)

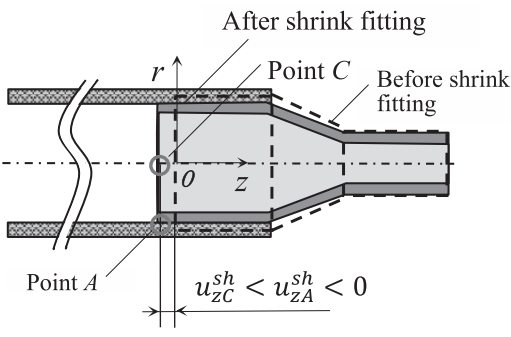

(b) Displacement (Model 2D-alt.)

Fig. 7. Stress along the shaft and the inside plate due to shrink fitting when $\delta / \mathrm{d}=0.2 \times 10^{-3}$. 
in Fig. 8 in order to discuss the coming out. Initial position of the shaft before shrink fitting is defined by the coordinate ( $r, z)$ as shown in Fig. 8. Then, relative displacement $\mathrm{u}_{\mathrm{zA}}$, $\mathrm{u}_{\mathrm{zC}}$ from the initial position is considered. Figure 8 shows the coming out of the plate due to the initial load. The coming out of the plate at point $\mathrm{A} u_{z A}^{N=0}$ occurs in the negative direction due to shrink fitting as shown in Fig. 6. Then, the coming out in the positive direction occurs due to the initial load. Here $u_{z A}^{N=0}$ and $u_{z C}^{N=0}$ are defined as the initial values $\mathrm{N}=0$ considering the effect of the initial load.

Figure 9 shows the displacement of the point A in Fig. 8 under two different shrink fitting ratios $\delta / \mathrm{d}$. Here, $\delta / \mathrm{d}=$ $0.2 \times 10^{-3}$ is commonly used for real ceramic sleeve rolls and $\delta / \mathrm{d}=0.01 \times 10^{-3}$ is an example of small shrink fitting ratio. In Fig. 9(a), the point a refers to displacement $u_{z A}^{s h}$ due to shrink fitting. While point a' in Fig. 9(a) refers to displacement $u_{z A}^{N=0}$ due to the initial load. In Fig. 9, the horizontal axis is number of cycle N. Here, the initial load after shrink fitting is corresponding to the number of cycle $\mathrm{N}=0$, while alternate load up and down once is corresponding to $\mathrm{N}=1$. Displacement at point $\mathrm{A} u_{z A}$ is indicated until $\mathrm{N}=40$.

Under the standard ratio, $\delta / \mathrm{d}=0.2 \times 10^{-3}$, displacement at point $\mathrm{A}$ is up and down as shown in Fig. 9(a) depending on the alternate loading. After $u_{z A}$ increases from $\mathrm{N}=0$ to $\mathrm{N}=5, u_{z A}$ becomes constant and decreases slightly with

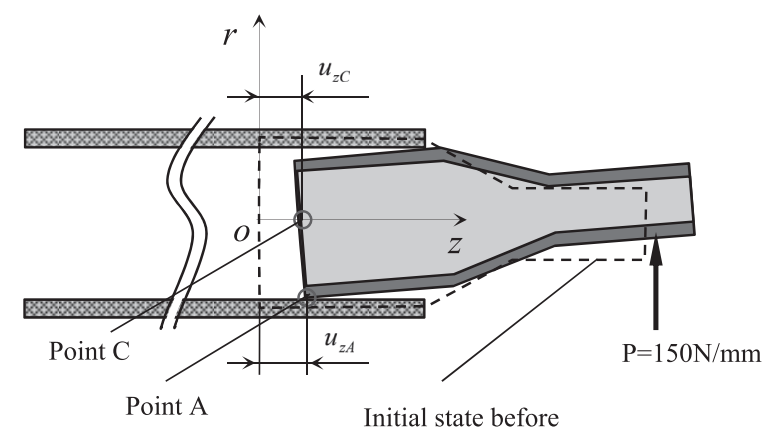

Fig. 8. Definition of the displacement of the plate due to shrink fitting and bending load (Model 2D-alt.).

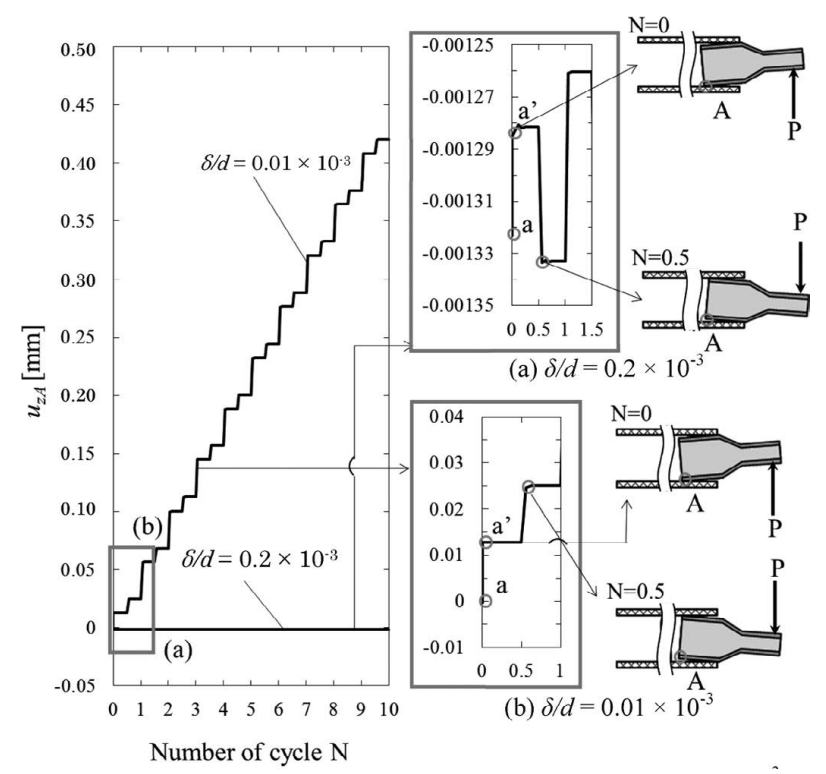

Fig. 9. Displacement $u_{z A}$ at point A vs. number of cycle $\mathrm{N}$ when $\delta / d=0.2 \times 10^{-3}, 0.01 \times 10^{-3}$. increasing N. On the other hand, under small shrink fitting ratio $\delta / \mathrm{d}=0.01 \times 10^{-3}, u_{z A}$ increases monotonously with increasing $\mathrm{N}$ as shown in Fig. 9(b).

Figure 10 shows relationship between $u_{z C}$ and number of cycle N. Here, the center point $\mathrm{C}$ in Fig. 8 is focused in order to discuss the coming out criteria. Under small shrink fitting ratio, displacement $u_{z C}$ increases monotonously as shown in Fig. 10(b) indicating that the coming out occurs easily. However, for standard shrink fitting ratio $\delta / d=0.2 \times 10^{-3}$, displacement increases with increasing $\mathrm{N}$ when $\mathrm{N}$ is small as shown in Fig. 10(a). In particular, since the coming out behavior is significantly different at $\mathrm{N}=5$ or less, the coming out should be judged after $\mathrm{N}=5$ or more.

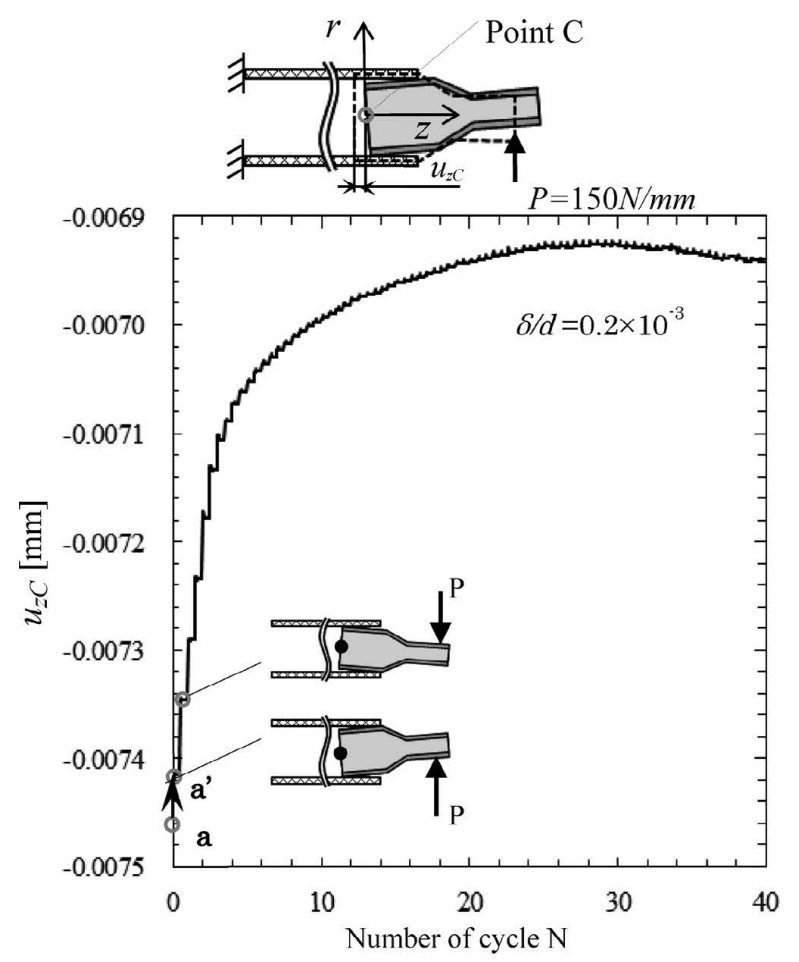

(a) Fitting ratio for $\delta / d=0.2 \times 10^{-3}$

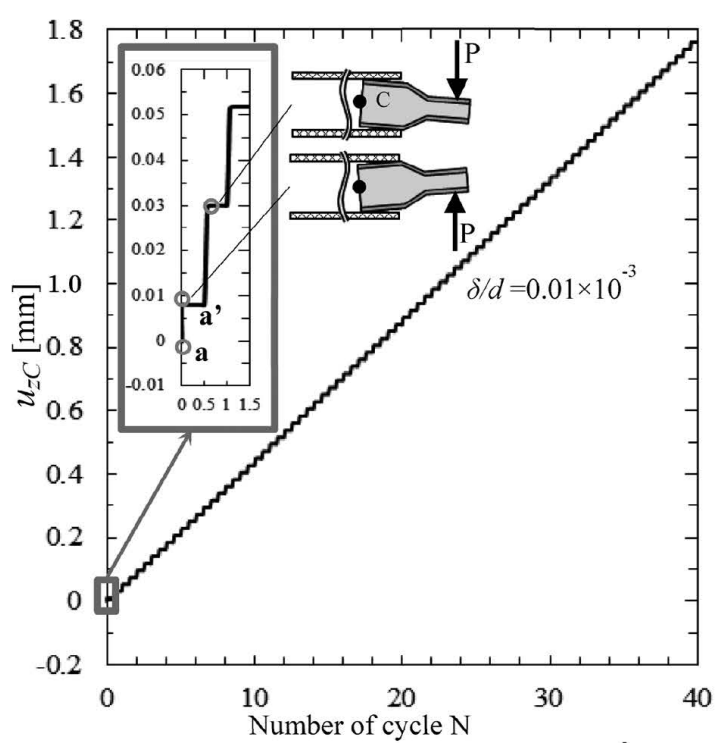

(b) Fitting ratio for $\delta / d=0.01 \times 10^{-3}$

Fig. 10. Displacement $u_{z C}$ at point $\mathrm{C}$ vs. number of cycle $\mathrm{N}$ for $\delta / d=0.01 \times 10^{-3}$. 


\section{Comparison of Coming Out Behavior Obtained from 2D and 3D Model}

Figures 11 and 12 show displacement $\mathrm{u}_{\mathrm{zC}}$ vs. $\mathrm{N}$ obtained from the $3 \mathrm{D}$ rotation load model (3D-rot.), the $3 \mathrm{D}$ alternate load model (3D-alt.), and the 2D alternate load model (2Dalt.). These models are explained in detail in Figs. 2, 3, 4.

Under a larger shrink fitting ratio, $\delta / \mathrm{d}=0.2 \times 10^{-3}$ as shown in Fig. 11, although the displacement is in the coming out direction at the first few cycle, the behavior is not simple. Since the number of cycle can be reached until $\mathrm{N}=40$ by using $2 \mathrm{D}$ model and $u_{z C}$ becomes nearly constant for larger value of $\mathrm{N}$, it can be judged that the coming out does not occur.

It is seen that the coming out cannot be evaluated accu-

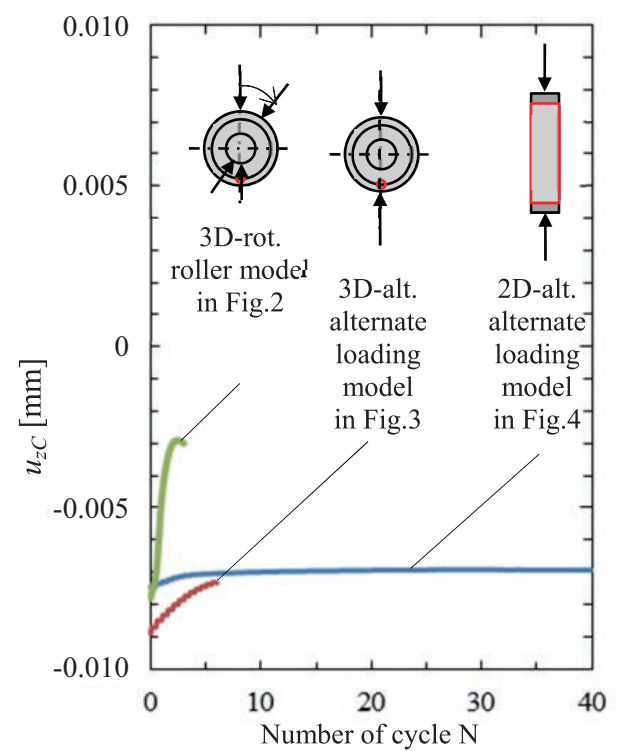

Fig. 11. Displacement $u_{z C}$ vs. number of cycle $\mathrm{N}$ for $3 \mathrm{D}$ real roller model, $3 \mathrm{D}$ alternate loading model and $2 \mathrm{D}$ alternate loading model under $\delta / d=0.2 \times 10^{-3}$. (Online version in color.)

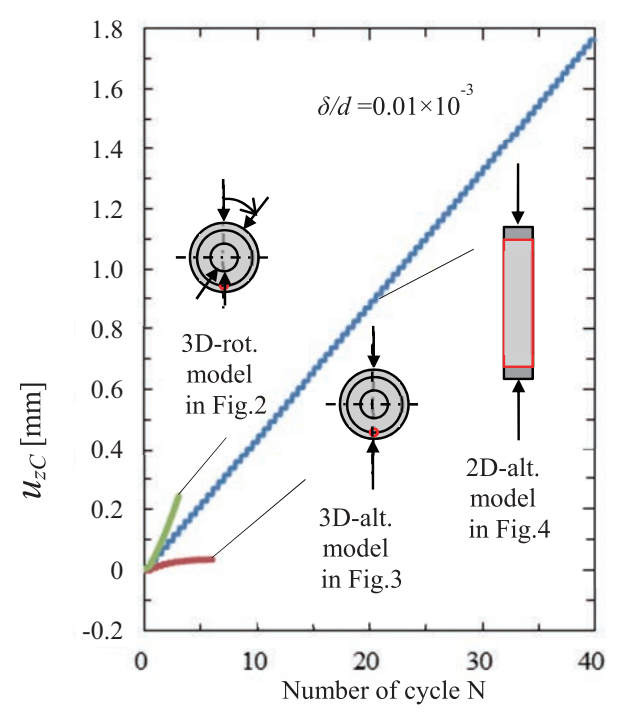

Fig. 12. Displacement $u_{z C}$ vs. number of cycle $\mathrm{N}$ for $3 \mathrm{D}$ real roller model, 3D alternate loading model and 2D alternate loading model under $\delta / d=0.01 \times 10^{-3}$. (Online version in color.) rately when $\mathrm{N}=5$ or less. Moreover, as shown in Fig. 12, under smaller shrink fitting ratio, the 3D alternate load model indicates uncertain behavior under small $\mathrm{N}$, and therefore, the coming out is difficult to be identified. Figures 11 and 12 shows that the 2D alternate loading model is useful. In the following discussion, in order to predict the coming out correctly, the 2D alternate load model will be used to obtain the results for larger N.

\section{Identification of the Coming Out by Using 2D Model}

In the previous chapter, it is seen that alternate load model (2D alt.) may predict the coming out behavior accurately. In this chapter, effects of the magnitude of the load and the shrink fitting ratio on the coming out will be investigated.

\subsection{Effect of the Magnitude of the Load on the Coming Out Behavior}

The standard force $18 \mathrm{kN}$ in the $3 \mathrm{D}$ model is equivalent to the distributed load $\mathrm{P}=150 \mathrm{~N} / \mathrm{mm}$ in $2 \mathrm{D}$ model because $2 \mathrm{D}$ model has the width $120 \mathrm{~mm}$ and the load is $150 \mathrm{~N} / \mathrm{mm} \times 120 \mathrm{~mm}=18 \mathrm{kN}$. The coming out behavior can be examined by changing the magnitude of the load. Here, $\mathrm{P}=300 \mathrm{~N} / \mathrm{mm}$ and $\mathrm{P}=600 \mathrm{~N} / \mathrm{mm}$ are also considered in order to determine the threshold condition of the coming out.

Figure 13 shows the effect of the magnitude of the load on the coming out under the shrink fitting ratio $\delta / d=0.2 \times 10^{-3}$. From the graph, the large load $\mathrm{P}$ causes the large z-displacement $u_{\mathrm{zC}}$. Displacement $u_{\mathrm{zC}}$ tends to increase at $\mathrm{N}=0-4$ independent of the magnitude $\mathrm{P}$. Then, after $\mathrm{N}=4$, it is seen that under $\mathrm{P} \geq 650 \mathrm{~N} / \mathrm{mm}$, displacement $\mathrm{u}_{\mathrm{zC}}$ increases significantly indicating that the coming out occurs. After $\mathrm{N}=4$, it is seen that for $\mathrm{P} \leq 640 \mathrm{~N} / \mathrm{mm}, \mathrm{u}_{\mathrm{zC}}$ becomes constant or decreases indicating that the coming out does not occur. It can be regarded that $\mathrm{P}=640 \mathrm{~N} / \mathrm{mm}$ is the threshold value of the coming out.

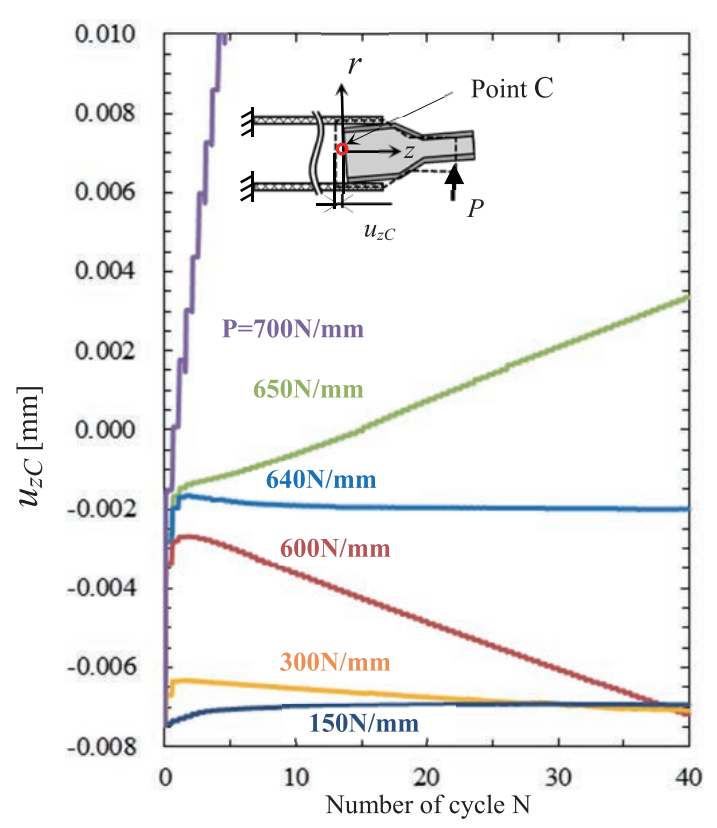

Fig. 13. Displacement $u_{z C}$ vs. number of cycle $N$ for different load $\mathrm{P}$ when $\delta / d=0.2 \times 10^{-3}$. (Online version in color.) 


\subsection{Effect of the Shrink Fitting Ratio}

Here, several shrink fitting ratios are considered. Figure 14 shows the effect of the shrink fitting ratio upon z-displacement $u_{\mathrm{zC}}$. It is found that the large shrink fitting ratio causes negative $u_{\mathrm{zC}}$ at $\mathrm{N}=0$ due to the compressive stress. For $\mathrm{N}=0-40, u_{\mathrm{zC}}$ increases significantly with increasing $\mathrm{N}$ under the small shrink fitting ratios, $\delta / \mathrm{d}=0.01 \times 10^{-3}$ and $\delta / \mathrm{d}=0.03 \times 10^{-3}$, therefore, the coming out of the shaft occurs easily. On the other hand, displacement $u_{\mathrm{zC}}$ becomes constant or decreases under shrink fitting ratios, $\delta / \mathrm{d}=0.1 \times 10^{-3}, \delta / \mathrm{d}=0.2 \times 10^{-3}$ and $\delta / \mathrm{d}=0.4 \times 10^{-3}$, therefore, the coming out of the shaft does not occur. It may be concluded that the threshold value exists between

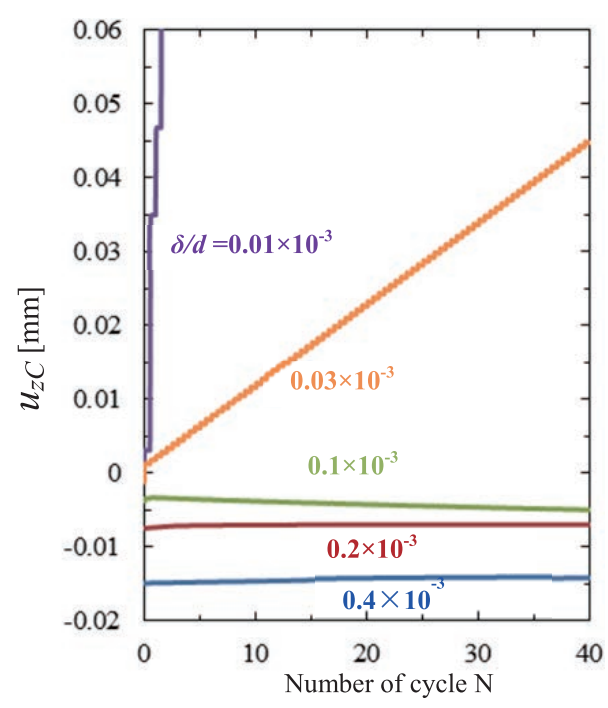

Fig. 14. Displacement $u_{z C}$ vs. number of cycle $N$ for different shrink fitting ratio $\delta / d$ when $\mathrm{P}=150 \mathrm{~N} / \mathrm{mm}$. (Online version in color.) $\delta / \mathrm{d}=0.03 \times 10^{-3}$ and $\delta / \mathrm{d}=0.1 \times 10^{-3}$.

\section{Discussion of the Coming Out Mechanism}

Effects of the magnitude of the load and the shrink fitting ratio were successfully discussed in the previous chapter. In this chapter, the coming out mechanism will be considered by focusing on the stress at point A changed due to the cyclic loading.

\subsection{Shear Stress at the End of Shrink Fitted Plate under Different Load}

Under the large shrink fitting ratio, $\delta / \mathrm{d}=0.2 \times 10^{-3}$ as shown in Fig. 15(a), shear stresses are compared when $\mathrm{N}=0$ and $\mathrm{N}=40$. It can be seen that $\tau_{\mathrm{rz}}$ does not change very much at point $\mathrm{A}$. In other words, the effect of bending load does not change very much at point A. Figure 15 (b) shows shear stress $\tau_{\mathrm{rz}}$ distribution at the contact surface when $\mathrm{N}=0$ and $\mathrm{N}=40$ under $\delta / \mathrm{d}=0.01 \times 10^{-3}$. Under this small shrink fitting ratio, the shear stress at the fitting area is almost zero when $\mathrm{N}=0$, except at the outer plate end. However, the shear stress distributions greatly change when $\mathrm{N}=40$. It should be noted that the shear stress direction is reversed to the negative value at point $\mathrm{A}$, the lower end of inside plate.

As a result, under $\delta / \mathrm{d}=0.2 \times 10^{-3} \tau_{\mathrm{rz}}$ does not change very much between $\mathrm{N}=0$ and $\mathrm{N}=40$, which means that the coming out does not occur. In contrast, under $\delta / \mathrm{d}=0.01 \times 10^{-3}$ shear stress $\tau_{\text {rz }}$ changes very much when $\mathrm{N}=40$ compared to the stress when $\mathrm{N}=0$. It indicates that the coming out of the inner plate occurs.

Figure 16(a) shows the relation between shear stress $\tau_{\mathrm{rz}}$ at point $\mathrm{A}$ and the number of cycle under different load $\mathrm{P}$ when $\delta / \mathrm{d}=0.2 \times 10^{-3}$. Here, point A can be regarded as the point where most likely to slip. Figures $16(\mathrm{~b}), 16(\mathrm{c})$ shows the

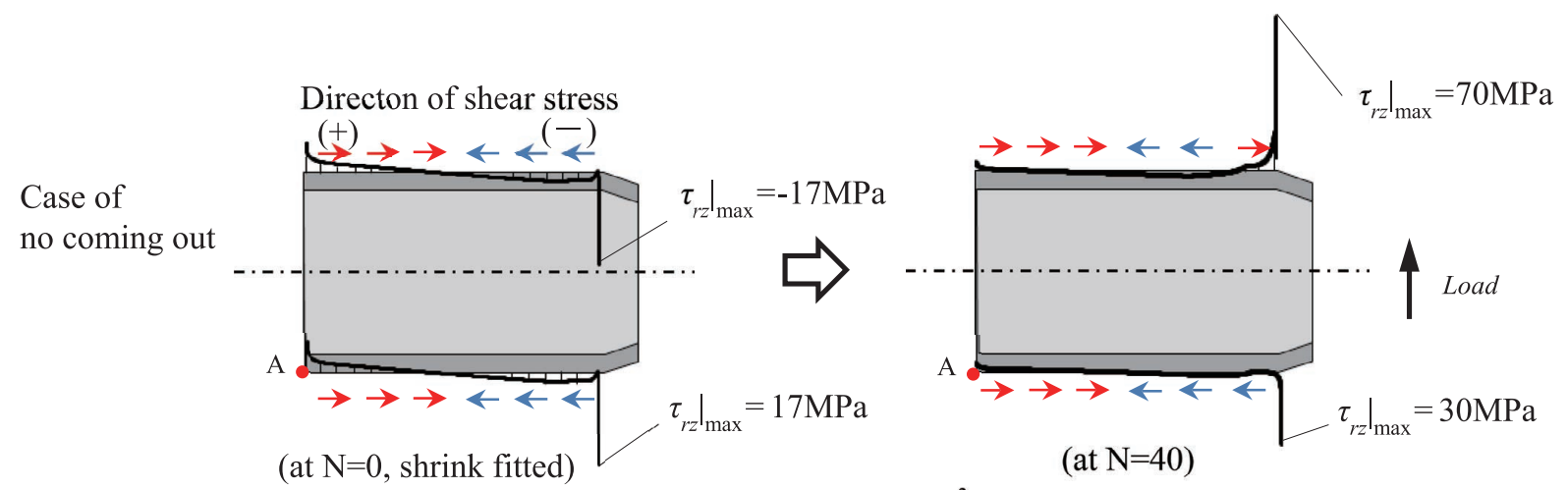

(a) $\tau_{r z}$ for $\delta / d=0.2 \times 10^{-3}$

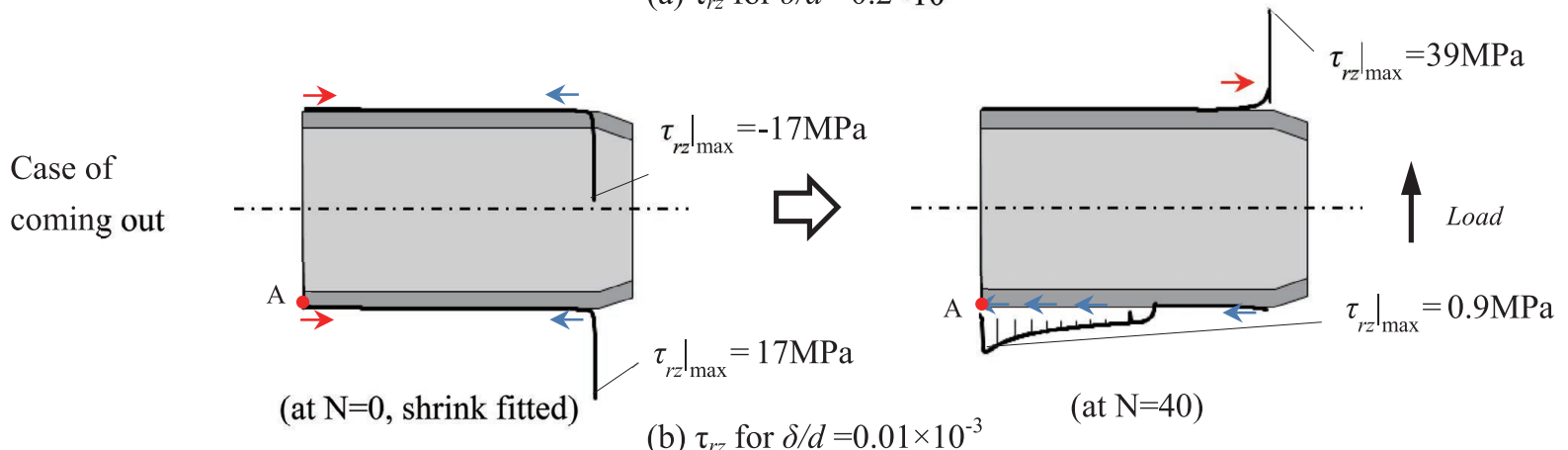

(b) $\tau_{r z}$ for $\delta / d=0.01 \times 10^{-3}$

Fig. 15. Shear stress distribution $\tau_{r z}$ for (a) $\delta / d=0.2 \times 10^{-3}$ and (b) $\delta / d=0.01 \times 10^{-3}$. (Online version in color.) 


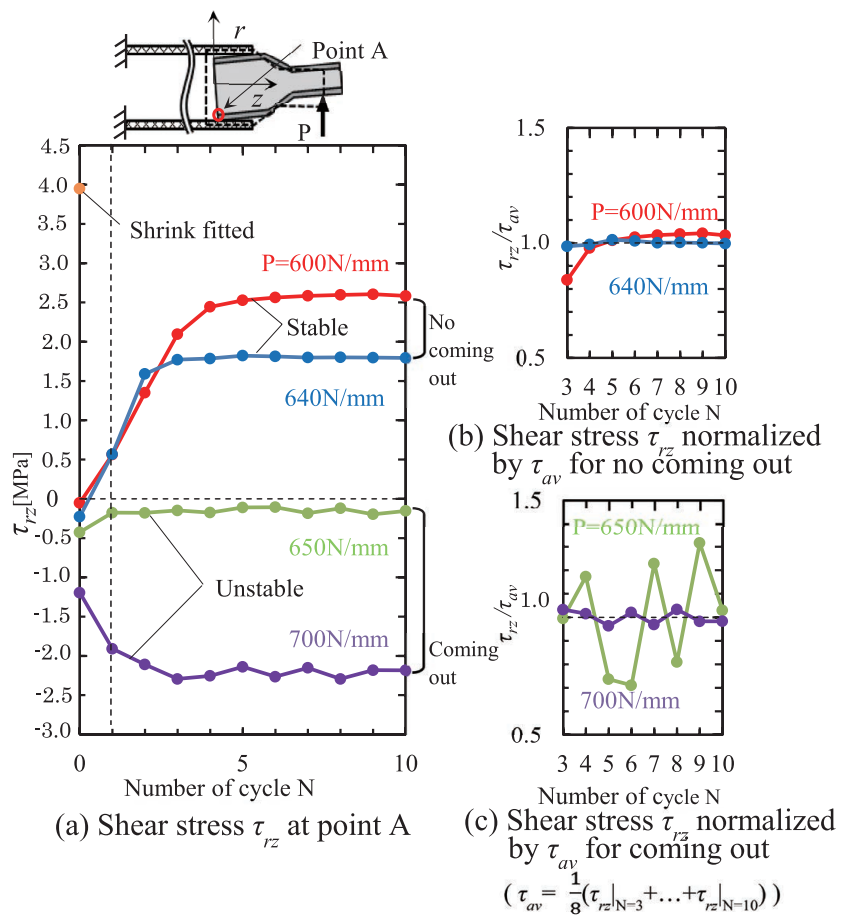

Fig. 16. Shear stress $\tau_{r z}$ at point $A$ vs. number of cycle $N$ when $\delta / d=0.2 \times 10^{-3}$. (Online version in color.)

relative shear stress $\tau_{r z} / \tau_{a v}$ normalized by the average stress defined as $\tau_{a v}=\frac{1}{8}\left(\tau_{r z} \mathrm{I}_{N=3}+\cdots+\tau_{r z} \mathrm{I}_{N=10}\right)$. Under $\mathrm{P}=600 \mathrm{~N} /$ $\mathrm{mm}$ and $\mathrm{P}=640 \mathrm{~N} / \mathrm{mm}$, the coming out does not occur when the positive shear stress, $\tau_{\mathrm{rz}}$ becomes nearly constant after $\mathrm{N}=2$. On the other hand, under $\mathrm{P}=650 \mathrm{~N} / \mathrm{mm}-700 \mathrm{~N} / \mathrm{mm}$, the coming out occurs after $\mathrm{N}=1$ when the negative shear stress, $\tau_{\mathrm{rz}}$ moves up and down unstably. From Fig. 16, the coming out of the inner plate can be judged easily after $\mathrm{N}=1$ from the shear stress direction at point $\mathrm{A}$.

When the coming out does not occur, the effect of the loads on point A may be very small. Although a small strain may occur at point $\mathrm{A}$, the contact state does not change very much because the inner and the outer plate are attached tightly. Therefore, the shear stress at point A becomes a constant value. On the other hand, when the coming out occurs under larger loads, the loads affect the stress at point A quite largely, and therefore, the contact status between the inner and outer plate is changed. The alternate load causes stick-slip around this area and the shear stress at point A is fluctuated.

\subsection{Displacement at the End of Shrink Fitted Plate under Different Load}

Figure 17 shows relative displacement $\Delta \mathrm{u}_{\mathrm{zA}}=\left.\mathrm{u}_{\mathrm{zA}}\right|_{\text {shaft }}{ }^{-}$ $\left.\mathrm{u}_{\mathrm{zA}}\right|_{\text {sleeve }}$ at point $\mathrm{A}$ until $\mathrm{N}=10$. When the coming out does not occur under $\mathrm{P}=640 \mathrm{~N} / \mathrm{mm}$ and $\mathrm{P}=600 \mathrm{~N} / \mathrm{mm}$, relative displacement $\Delta \mathrm{u}_{\mathrm{zA}}$ becomes smaller and nearly constant for $\mathrm{N}>3$. On the other hand, when the coming out occurs under $\mathrm{P}=700 \mathrm{~N} / \mathrm{mm}$ and $\mathrm{P}=650 \mathrm{~N} / \mathrm{mm}$, the relative displacement is fluctuated.

Figure 18 shows the relationship between relative displacement $\Delta \mathrm{u}_{\mathrm{zA}}$ and shear stress $\tau_{\mathrm{rz}}$ at point $\mathrm{A}$. The number of cycle, $\mathrm{N}=3-10$ is considered because the shrink fitting effect becomes smaller after $\mathrm{N}=3$. Under $\mathrm{P}=700 \mathrm{~N} / \mathrm{mm}$ and

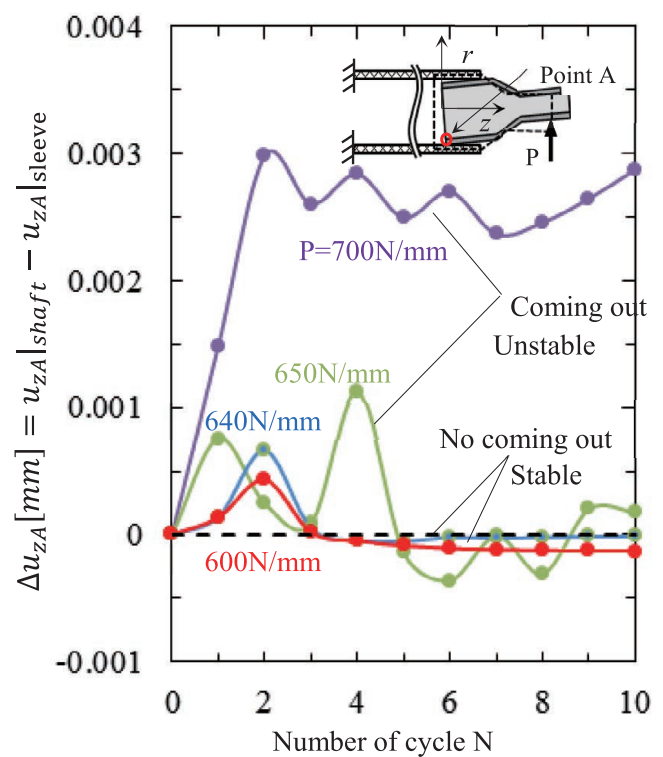

Fig. 17. Relative displacement increment $\Delta u_{z A}$ vs. number of cycle $\mathrm{N}=1-10$ for $2 \mathrm{D}$ alternate loading model. (Online version in color.)

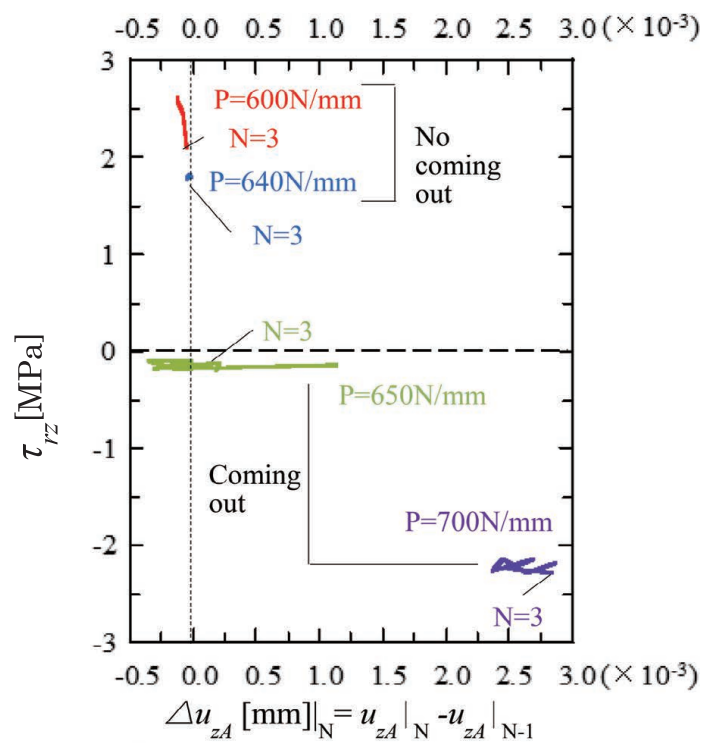

Fig. 18. Sheer stess $\tau_{r z}$ vs. relative displacement increment $\Delta u_{z A}$ at number of cycle $\mathrm{N}=3-10$ for $2 \mathrm{D}$ alternate loading model (Online version in color.)

$\mathrm{P}=650 \mathrm{~N} / \mathrm{mm}$, the coming out can be identified because $\Delta \mathrm{u}_{\mathrm{zA}}-\tau_{\mathrm{rz}}$ relationship is randomly distributed due to the stick-slip phenomenon. Therefore, the shear stress is greatly fluctuated in a wave form. On the other hand, for $\mathrm{P}=600 \mathrm{~N} /$ $\mathrm{mm}$ and $\mathrm{P}=640 \mathrm{~N} / \mathrm{mm}$, the coming out does not occur when $\Delta \mathrm{u}_{\mathrm{zA}}$ is close to zero, and $\tau_{\mathrm{rz}}$ has a large positive value. In other words, the coming out does not occur if there is no large fluctuation at point $\mathrm{A}$.

\subsection{Shear Stress at the End of Shrink Fitted Plate under Different Shrink-fitting Ratio}

Figure 19 shows the effect of the shrink fitting ratio on the coming out focusing on shear stress $\tau_{\mathrm{rz}}$ at point A. The coming out does not occur when $\delta / \mathrm{d}=0.4 \times 10^{-3}$, $\delta / \mathrm{d}=0.2 \times 10^{-3}$ and $\delta / \mathrm{d}=0.1 \times 10^{-3}$. Here, the shear stress at point $\mathrm{A}$ is stable for each cycle and the value is positive. On 


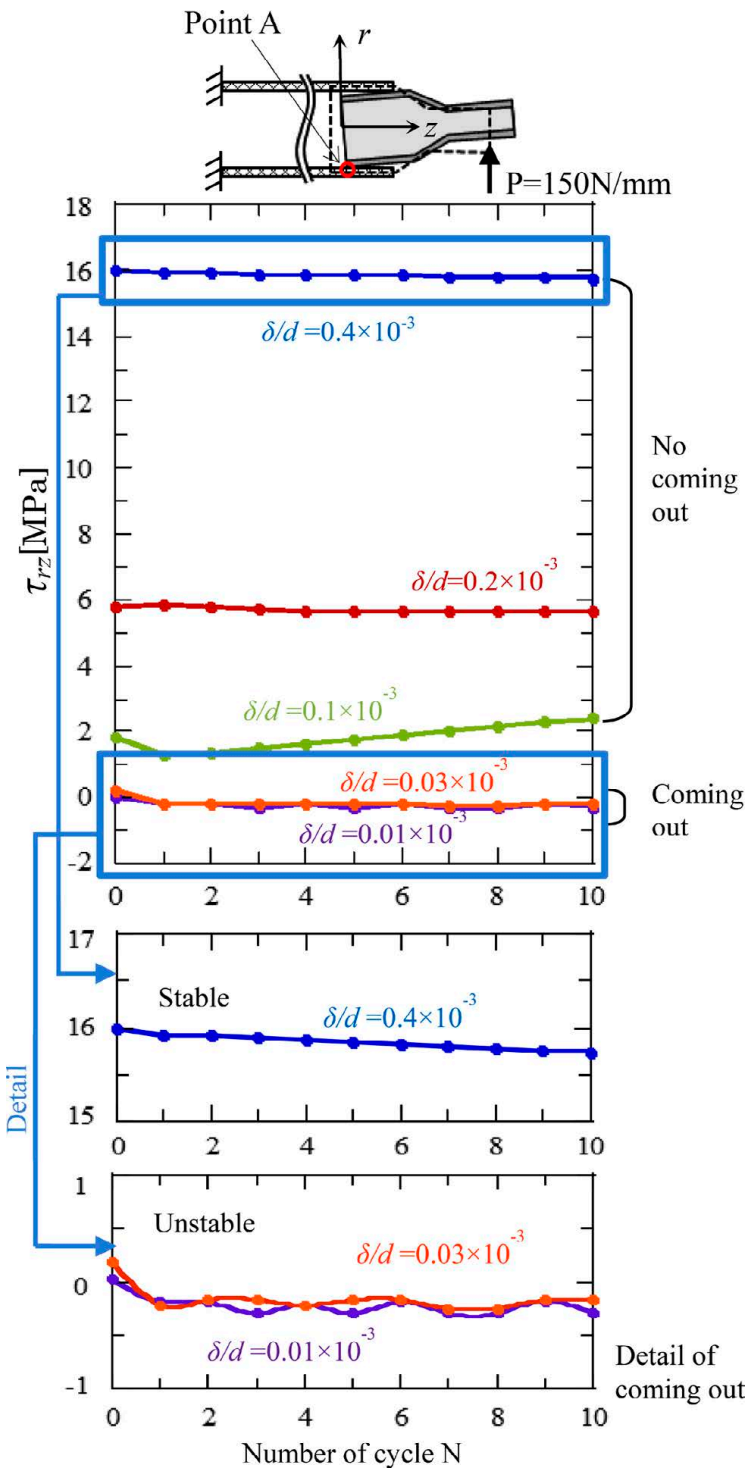

Fig. 19. Shear stress $\tau_{r z}$ at point $A$ vs. number of cycle $N$ when $\mathrm{P}=150 \mathrm{~N} / \mathrm{mm}$. (Online version in color.)

the other hand, the coming out occurs when $\delta / \mathrm{d}=0.03 \times 10^{-3}$ and $\delta / \mathrm{d}=0.01 \times 10^{-3}$. The shear stress at point $\mathrm{A}$ is unstable and the value is negative. This coming out behavior is similar to the result shown in Fig. 17.

Based on the investigation above, the coming out behavior can be summarized in terms of the shear stress and displacement at point A due to alternate load and shrink fitting ratio. (1) When the coming out occurs, the shear stress value at point $\mathrm{A}$ is negative and unstable. Moreover, the relative displacement varies unstably with increasing number of cycle $\mathrm{N}$ because the micro stick-slip occurs. (2) When the coming out does not occur, the positive shear stress at point $\mathrm{A}$ is stable and the displacement at point A takes very small value close to zero.

\section{Conclusions}

Steel conveying rollers are used in the heating furnace for producing high-quality steel plates for automobiles. The new roller consists of ceramic sleeve and steel shaft connected only under a small shrink fitting ratio because of the brittleness. To analyze the coming out problem more efficiently, in this paper, the two-dimensional shrink fitted structures were considered. The conclusions can be summarized as follows.

(1) The coming out behavior is realized in the simulation by using 2D model until larger number of loading cycle $\mathrm{N}$. By focusing on the shear stress and displacement at the inner plate end, the coming out behavior can be identified.

(2) The effect of the magnitude of the alternate loads was discussed. If the load is larger than the threshold value, the coming out happens.

(3) The effect of the shrink fitting ratio was discussed. If the shrink fitting ratio is smaller than the threshold value, the coming out happens.

(4) The coming out mechanism was discussed focusing on the contact shear stress at the inner plate end. When the coming out occurs, the shear stress is unstable and the value is changed from positive to negative. On the other hand, when the coming out does not occur, the shear stress is stable and the value is always positive.

(5) By focusing on the relative displacement at the inner plate end, the coming out occurs when the displacement is fluctuated in a similar way of the shear stress. In other words, the coming out occurs when a stick-slip phenomenon appears. The coming out does not occur when the displacement is stable and nearly zero.

\section{Acknowledgement}

The authors wish to express our thanks to the members of our group, Seiichi KUMASAKI, Toshikazu IMAKADO and Yutaro SHIMODA for their kind support to this study.

\section{REFERENCES}

1) M. Fujii, A. Yoshida, J. Ishimaru, S. Shigemura and K. Tani: Trans. Jpn. Soc. Mech. Eng. C, 72 (2006), 1354.

2) T. Ono: J. Jpn. Soc. Mech. Eng., 86 (1983), 470.

3) C. Liour, T. Mori, H. Kobayashi and T. Mitamura: JCS-Japan, 98 (1990), 348.

4) W. Li, N-A. Noda, H. Sakai and Y. Takase: J. Solid Mech. Mater. Eng., 5 (2011), 14.

5) W. Li, N. A. Noda, H. Sakai and Y. Takase: Key Eng. Mater., 452-453 (2011), 241.

6) A. Rusin, G. Nowak and W. Piecha: Eng. Fail. Anal., 34 (2013), 217.

7) S. Harada, N. A. Noda, O. Uehara and M. Nagano: Trans. Jpn. Soc. Mech. Eng. A, 57 (1991), 1637.

8) E. Ogawa, K. Shimizu, S. Hamayoshi, N. Kumagai, Y. Ohtsubo, N. A. Noda, Y. Takase, K, Kishi, K. Shobu, T. Tabaru, E, Maeda, S. Koga and T. Matsuda: Hitachi Metals Tech. Rev., 28 (2012), 50.

9) M. Tsuyunaru, N. A. Noda, Hendra and Y. Takase: Trans. Jpn. Soc. Mech. Eng. A, 74 (2008), 919.

10) N. A. Noda, Hendra. Y. Takase and M. Tsuyunaru: J. Solid Mech. Mater. Eng., 2 (2008), No. 2, 1410.

11) N. A. Noda, M. Yamada, Y. Sano, S. Sugiyama and S. Kobayashi: Eng. Fail. Anal., 15 (2008), 261.

12) N. A. Noda, Hendra, M. Oosato, K. Suzumoto, Y. Takase and W. Li: Key Eng. Mater., 462-463 (2011), 1140.

13) S. Matsuda, D. Suryadi, N. A. Noda, Y. Sano, Y. Takase and S. Harada: Trans. Jpn. Soc. Mech. Eng. A, 79 (2013), 989.

14) N-A. Noda, D. Suryadi, S. Matsuda, Y. Sano and Y. Takase: ISIJ Int., 55 (2015), 2416.

15) C. E. Truman and J. D. Booker: Eng. Fail. Anal., 14 (2007), 557.

16) N. Antoni: Appl. Math. Mech., 37 (2003), 2352.

17) N. A. Noda, Y. Sano, Y. Takase, S. Harada, D. Suryadi and S. Kumasaki: Tetsu-to-Hagané, 101 (2015), 10 (in Japanese).

18) N. A. Noda, D. Suryadi, S. Kumasaki, Y. Sano and Y. Takase: Engi. Fail. Anal., 57 (2015), 219. 